\title{
POTENTIAL USAGE OF GIS IN EDUCATION
}

\author{
Marko Stojanović* \\ Viktor Marković, \\ Zoran Kričković, \\ Radoje Banković \\ Military Geographical Institute, \\ Belgrade, Serbia
}

Correspondence:

Marko Stojanović

e-mail:

stojanovicm80@yahoo.com

\begin{abstract}
:
This paper tends to show potential usage of GIS in educational process. Contemporary educational process is unimaginable without involving innovations in all forms of teaching processes. These innovations tend to develop dialectical approach in observation of real world objects, phenomenon and processes. The practical implementations of GIS as well as requirements are considered regarding foreign experience and solutions.
\end{abstract}

Keywords:

GIS, education, Web GIS, teaching curriculum.

\section{INTRODUCTION}

The contemporary educational process is unimaginable without involving innovations in all forms of teaching process. These innovations tends to develop dialectical approach in the real world objects observation, phenomenon and processes. Engagement of trending science achievements, enables a higher quality teaching process. Research that includes geospatial content is a complex task and implies a detailed analysis of all relevant objects, phenomenon and processes in geospace. The actual level of technological development enables creation of new techniques and tools that makes that process easier and faster. Technology of Geographical Information Systems (GIS) is one of such technologies whose usage has become unavoidable in the sphere of all sciences which include work with geospatial data. Using GIS gives students an opportunity to, in an easier and precise way, get the answer to spatial related questions and, at the same time, get results of their research visualized in a customized manner. This task is, in the first place, enabled by using GIS software whose main goal in this case, is to give students the ability of better perception of spatial relations and real world objects. Resources like GIS software and imagery, and the way they are integrated in the teaching process, have a potential to greatly increase the quality of the teaching process as well as to boost both interest and motivation of students for geospatial related sciences. Quality and suitability of chosen resources and a way they are used by students, represent key factors which affects the success of the learning process [1]. 


\section{GEOGRAPHICAL INFORMATION SYSTEMS}

The use of GIS, gives the opportunity to acquire spatial related knowledge and skills, allows us to interpret spatial data in new ways as well as discover new connections, relations and trends in geospace. GIS can be defined as an arranged set of data, software, hardware, network and personnel in purpose of collecting, analyzing, reshaping, handling, updating, storing, representing and transferring different types of spatial information. The greatest advantage of GIS system represents its unique ability to integrate spatial related information with the information that does not possess spatial character [2].

Geoinformation system consists of four base elements which are: data, personnel, hardware and software, beside these elements, together with the development of the internet technology and GIS itself, the structure of the system is also defined with a computer network and the applied standards.

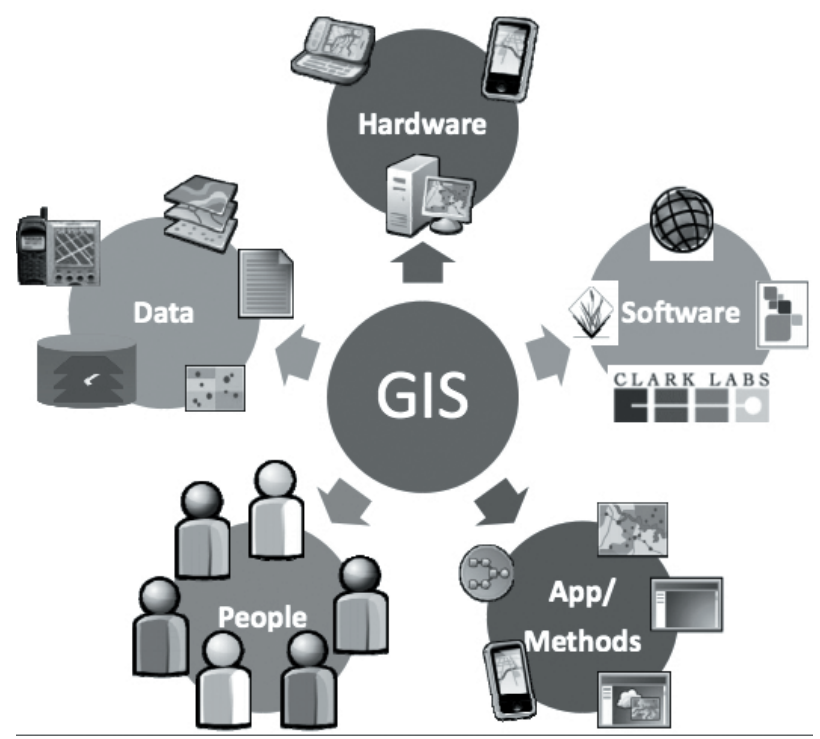

Fig. 1. Components of the GIS [3].

Spatial phenomenon are presented visually in a raster or a vector data format. The vector data (point, line, shape) usually uses an adequate symbols. A pixel is the base of every raster data format. The number and the size of a pixels that create an image, define the resolution of a given image. All attributes (numerical, descriptional, images) are stored in a database which is interactively connected with its graphical representation. The database structure depends on a purpose for which is created in the first place, and, due to that, is created to match specific needs. GIS, together with a database, forms the unbreakable unity and, considering that aspect, can be said that GIS is a database system in which most of the data is spatially indexed and which manages numerous actions in order to provide the answers to the queries about the spatial entities which are stored in databases [4].

One of the most important element of the GIS is a personnel. These are skilled experts in the database design, implementation, maintenance and the software usage. GIS experts can be classified as managers, creators and users. The manager's main task is to question the functionality of the GIS through the engaged hardware, software, database and through specific cases of the implementation. The users are important for the GIS exploitation and their competence depend on the purpose of the system. The creator's task is to conduct system analysis, to design and upgrade the system through the programming [5].

The term "hardware", which is a basic component of the GIS, is standardized and it stands for all parts of the physical components of any information system. The hardware makes the material base of the information system and it consists of computers (PC, workstation), input-output components (plotters, scanners) and the storage media. The availability of the powerful hardware, led to easier distribution of the GIS applications and products and made easier for them to find their way to the end users. Recently, with the development of the internet and the computer network technologies, the GIS (one of its parts) has became more oriented to the network infrastructure and is known as a Web GIS. A fundament of this system consists of a network/internet architecture and servers which hosts the applicative software and databases while the end users are encouraged to access, edit and use the data through browsers (clients) [6].

The GIS engaged software include all parts of the programs, procedures and the joined documents on any system whose purpose is to process the geodata. Currently, worldwide there are numerous software with the general or specialized GIS purposes. Some of them are Autodesk, ESRI, Intergraf, Mapinfo, Smallworld, Idrisi etc.. Almost every of the commercially available GIS software, beside a basic edition, consists of the numerous extensions whose engagement determinate final price of the chosen software. Every GIS software is specific in its way and give more or less possibilities, depending on a specific need, but global approach and adoption of the GIS platforms, led to the standardization, so almost all of the GIS software solutions are compatible with each other. 


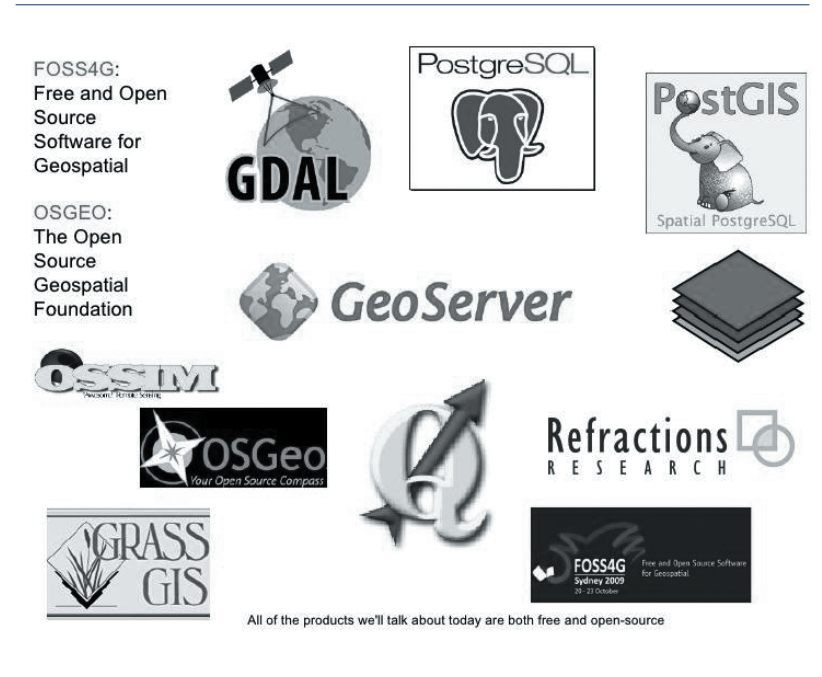

Fig. 2. Open Source software [7].

Beside the commercial, there are a number of the GIS software which is freeware (Open Source). In a sphere of the freeware GIS software, there are complete solutions which includes a free database (PostgreSQL with PostGIS extension, SQLite with SpatiaLite extension), a free client based GIS applications (GRASS, QGIS) and a free servers for the Web publishing of the geospatial data (MapServer, Geoserver). One of the drawback of using a freeware software solution (in most cases) is that there are no adequate user support or training [8].

Regardless of a software price, a GIS software is usually divided into categories [2]:

- Mobile GIS, is intended for the use of the GIS at the field.

- GIS add-ons and the libraries enable an additional functionality which is not accessible through the basic GIS software and in most cases, don't influence a common user experience.

- Desktop software which is used for the creation, management, arrangement, presentation and the analysis are usually divided into a GIS Editor, GIS Viewer or a GIS Analyst.

- Systems, whose purpose is the management of the spatial databases (Spatial Database Management Systems), find their use in a process of the data storage, although in most cases they have ability of the data manipulation and analysis.

- Client software (Web GIS) are ment for the presentation and access, over the internet, by using queries and analysis. There are a Thin Web GISwhich enables only querying and presentation and a Thick Web GIS- provides tools which allows complex analysis, arrangement and manipulation of the spatial data.
- Server GIS software allows access over the computer networks while in its base has the same function as a Desktop GIS software.

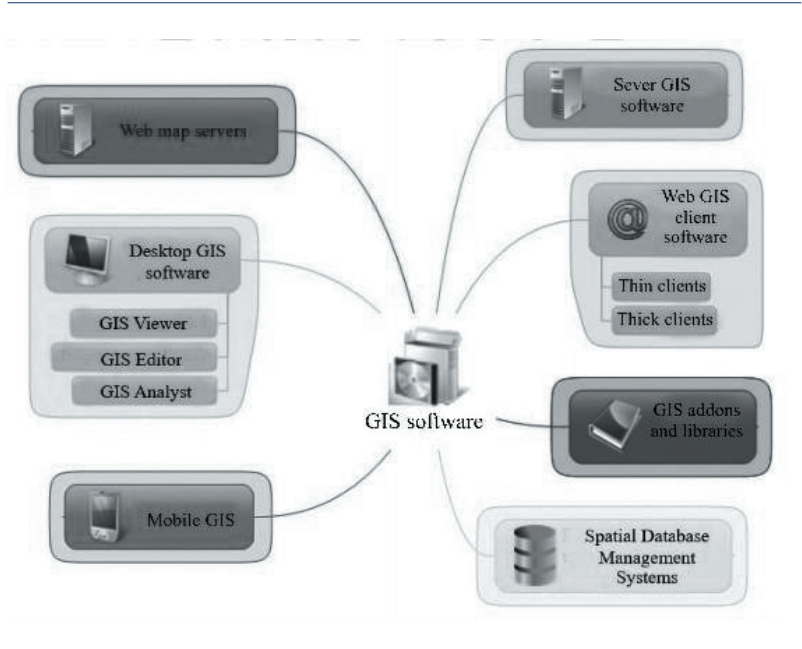

Fig. 3. Categories of GIS software [2].

The GIS, as a technology that implies the manipulation of the geospatial information, found its usage and became the inseparable part of the numerous sciences such as geography, geology, geophysics, agriculture, biology, sociology, history, political sciences, anthropology etc. The necessity and a fact is that the education system has to adopt the advantages that the GIS technology brings as well.

\section{IMPLEMENTATION OF THE GIS SERVICES IN THE EDUCATION PROCESSES}

In the developed countries, the GIS implementation in the education processes has been developed for many years. However, in most countries there are still not existing compliant methods for presenting teaching curriculum using GIS. It is mostly used for a geographic subject, but as the time passes, it is adopted by the other subjects as well. A GIS itself allows numerous data types and data sources to be used in the teaching process.

There is an opinion that the GIS is becoming important and the necessary technology which is used in order to improve the teaching process. At the same time, the implementation of the GIS requires certain resources like the data, personnel, hardware and a software. 


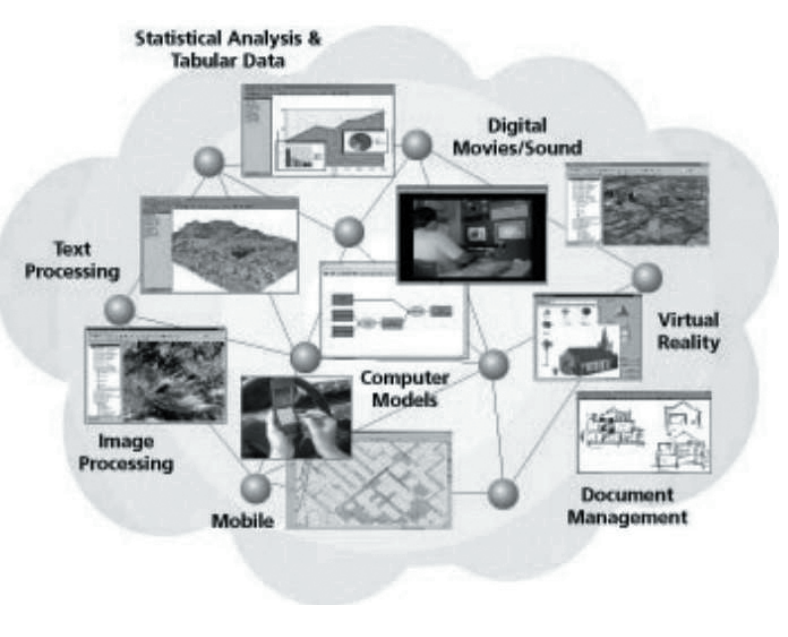

Fig. 4. Integration of different data types in GIS [2].

\section{Other countries examples}

In the Great Britain, implementing GIS in National curriculum started in 1991. A new technology and specialized tools are implemented in the aspect of the cartographic education. At the beginning, this innovation met with resistance of the teachers, as they were not yet prepared and adequately educated for the new technologies. The GIS was at the beginning of its expansion and still didn't find the application in the everyday life, there was little experience in his usage and the standards were still not exactly defined. Some number of the teachers managed to maintain new education concept and gain certain results in a GIS implementation in the education process.

In the USA, the GIS was implemented in the education process in 1992, but at a very low level. The key reason for that was in the teachers' informatics illiteracy and the rejection towards the new technologies as well as an education institutions material base. As private schools emerged, so the material and employees' conditions were advancing and the quality of a GIS implementation in the education process was getting better.

Germany adopted GIS in the education process systematically with a clearly defined plan, whit the outstanding results. A National curriculum reform was conducted resulting in a reduced extent and the aspect of the teaching curriculum and focusing to the informatics methods and the work techniques. Teachers who didn't have a basic GIS knowledge during university went to the extra GIS education, by the school decisions. The schools got the software and hardware components, a standardization of computer networks is conducted and the high speed Internet is implemented.
In Brazil, the necessity of application of the contemporary education system as the precondition for the comprehensive society development is noticed. In the accordance with this, the remote sensing and the GIS were implemented in the teaching curriculum for the high schools. Teachers accepted the new technologies and noticed their advantage, and their personal development is guided towards the new technologies. As a result, the efficiency and effectiveness of the teaching process is increased, as well as the functionality of the education system.

University of Miskolc in Hungary initiated a project on necessity of implementing GIS in a teaching process at the high school level. Basically, the project was aiming professional, informatics support to the teachers in order to implement a new content in a teaching curriculum and the GIS as a new teaching technology. The main goal of the project was based on a fact that through entire life education concept, nobody could feel neglected during the new technologies implementation in the educational process. This was very significant because the acceptance of the new methods and the teaching resources, as well as new content are crucial for the success. A research on understanding the importance of the GIS and its role in the education, the usage of this technology or intention of using GIS in a classroom and the necessity for the extra education is conducted in Hungary and in Greece. The results of the research showed next: every surveyed school has its own electronic classroom, the half of the history and economy teachers have never heard of the GIS, every geography and the informatics teacher is familiar with the term GIS as well as his basic functions. Only 5 percent of the surveyed teachers had GIS in their schools, from which half used it as a teaching resource in school, while nobody was holding lecture on it, almost all surveyed teachers expressed wish to use the GIS in a teaching process and to take part in some extra education programs. And, the most important, nobody from the surveyed teachers opposed to a GIS implementation in the high school education. [9].

Malaysia in 1996 took the initiative to develop national hub for the smart school system, whose part was the GIS as well, but they faced, as many other countries, lack of the computer literate workforce.

Many countries started, or took the initiative for the implementation of the GIS technology in the teaching curriculum with the more or less success. One of the main issues that appeared, especially in not so developed countries, is a deficiency of the computer literate 
workforce. That problem was recognized and the additional effort is invested in a teachers' education. Teachers' education is taken as the priority over the technical equipping, which still requires a significant financial resources for not so rich countries. Not only the teachers are recognized as a problem, but also the number of the IT personnel was insufficient, because of the complexity of a GIS system and its requirements for the maintenance and development. Consequently, the demand for a computer literate workforce and the IT professionals has grown dramatically [10].

\section{The possibilities of implementation of the GIS in Serbian education system}

A systematic analysis is needed for considering possibilities of implementing GIS in the Serbian education system, through the four GIS basic elements and defining the organization of the entire project.

Regarding the hardware, it is required for the schools to have a classroom equipped with the computers connected to the network, server, with access to the Internet, projector, some laptops and a GPS device. This is hard to be done in Serbia due to the economic situation, but the problem is possible to overcome by the usage of a computer, projector and a smart phone with a GPS possibility, but the Internet is mandatory. A server used for the data storage is possible to define at the level of city, region, or the entire state, and the access to data could be arranged through the VPN.

Software required for the GIS, considering a hierarchy, is divided into two basic groups: a basic software and the application software. Considering licensing, it is divided into the licensed (commercial) and the open source software (free). A basic software is comprised of an operating system (OS) and the standards. The choice of the OS is depending on the application software used for the GIS. Certain commercial software have versions for both the licensed OS and the open source OS, and the use of Web GIS is demanded only by the web browser. Considering all these facts, together with the economic situation in Serbia, the usage of the open source OS (Linux) solution is recognized as the optimal.

The choice of the system software (a database management system and the network software) is also derived from the previous analysis and the open source software (MySQL, PostgreSQL). The network software is, by default, integrated in the OS and is functioning by the TCP/IP language (Transmission Control Protocol/Internet Protocol). The choice of the application software is the most important in this phase of a project. On the market, there are numerous commercial and the open source application software. The commercial software are more complex, provide more possibilities, but demand more funds, whilst the user support in the open source software is insufficient or is charged extra. The optimal solution is the application software procurement with a built-in Web GIS (ESRI - ArcGIS Server and ArcGIS Desktop). The advantage of this software is a Web GIS support, numerous users on the Internet and the user support. Although, a license is not needed for the each computer, but only for a server component (in the level of school, municipality, state), and it is developed for the Linux as well as for the Windows.

Some data of the general geographic content, such as continents, states, population, hydrography are already built in this software. In that way, the application of the GIS is possible immediately after the installation and teachers' training. Next step is to create new databases and add new content. The data used for populating these databases are already available through the various portals and services. Using a Web GIS, all the data are stored in one place (school, municipality, state) and they are available for the others in the teaching process.

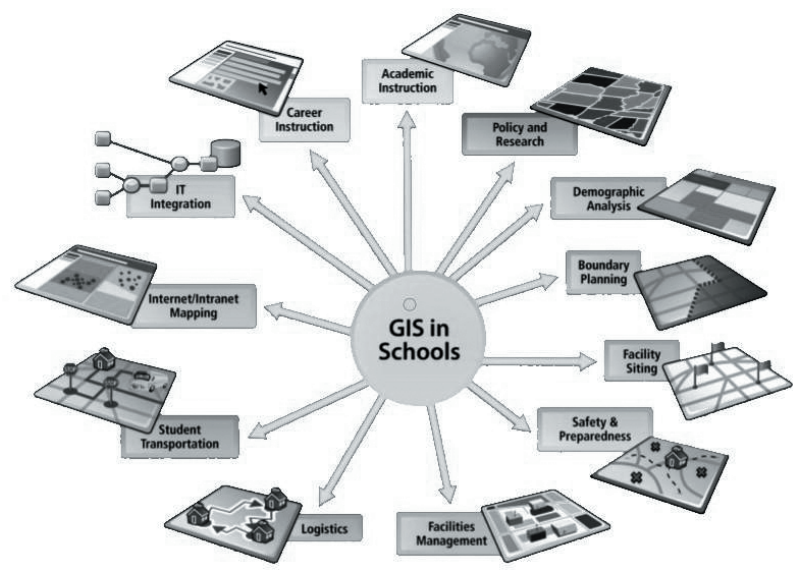

Fig. 5. GIS in Schools [11].

\section{CONCLUSION}

The GIS implementation in a teaching process helps the students in better observation, analysis and the interpretation of the spatial information. It is easier for the students to cope with various subject matters using the GIS tools for the modelling and the simulation, they develop analytic skills and understand the significance of the environment. On the other hand, teachers can use 
the contemporary teaching methods, by which students are the real subject of the teaching process. Through the GIS, monitoring of the students progress is more efficient and the students are motivated to adopt the new skills using the modern technologies.

However, the application of the GIS in a teaching process and education, in our country is at the beginning. There are almost none GIS contents in a teaching curriculum due to the many subjective and objective reasons. A new technology application, above all, depends on the certain conditions, such as teachers education, electronic classrooms, financial possibilities of the education institutions to provide an adequate software and hardware. By the straight and systematic organization, as well as the project application of the GIS implementation in the education system, using technical possibilities and tendency in the area of information technologies and the GIS, it is possible to reduce material resources needed for this complex task.

\section{REFERENCES}

[1] D. Lambert, \& D. Balderstone, Learning to Teach Geography in the Secondary School, London: RoutledgeFalmer, 2000.

[2] V. Jovanović, B. Đurđev, Z. Srdić, U. Stankov, Geografical Information Systems, Singidunum University of Belgrade and University of Novi Sad, 2012.

[3] [Online]. Available: https://lisdemo.libguides.com. [Accessed 28. 03. 2018.].

[4] T. R. Smith, S. Menon, J. L. Starr, J.E. Estess, "Requirements and principles for large scale GIS," International Journal of Geographical Information Systems, vol. 1, no. 1, pp. 13-31, 1987.

[5] N. Frančula, Digital Cartography, Zagreb: Faculty of Geodesy, 1999.

[6] A. Pavlović, Usage of GIS in teaching curriculum of Geography [Term paper], Belgrade: Faculty of Geography, 2013.

[7] [Online]. Available: https://www.slideshare.net/joelarson/free-gis. [Accessed 29. 03. 2018.].

[8] D. Radosavljević, GIS at local government - at Jagodina example [MSc Thesis], Belgrade: Faculty of Geography, 2016.

[9] G. Bartha, Objectives of GIS Teaching in Higher Education: developing experts or training teachers? [Project], University of Miskolc, 2003.

[10] M. N. N. Lee, "Education in Malaysia: towards vision 2020," School Effectiveness and School Improvement, vol. 10, no. 1, pp. 86-98, 1999.

[11] [Online]. Available: https:// jkerski@esri.com. [Accessed 29. 03. 2018.]. 